\section{O Caribe entre impérios: memória, cultura e política}

DÍAZ-QUIÑONES, Arcadio. A memória rota: ensaios de cultura e política. Tradução e organização de Pedro Meira Monteiro. São Paulo, Companhia das Letras, 2016. 344 páginas.

\section{Alejandra Josiowicz}

A memória rota traz uma série de ensaios acadêmicos e de intervenção cultural com foco no Caribe e suas complexidades sociais, culturais e políticas, publicados (a maior parte deles) pela primeira vez em português. Arcadio Díaz-Quiñones, crítico caribenho e intelectual latino-americano, professor da Universidade de Princeton, é uma figura central para o estudo da história intelectual e cultural da América hispânica, do Caribe, em particular de Porto Rico; suas reflexóes podem suscitar ricas e complexas comparaçóes com o Brasil, a partir de sugestivas relaçóes de "dessemelhança na semelhança”, parafraseando ao autor.

Com essa frase, Díaz-Quiñones refere-se à sensação de estranheza em razão das diferenças políticas, culturais e geográficas entre o Brasil e o Caribe diferenças também da língua, da fala e dos circuitos orais - que paradoxalmente funcionam não como obstáculos, mas como estímulos para a comparação entre imaginários gerados por marcas ideológicas comuns. Assim, o livro abre possibilidades para refletir, em termos comparativos, sobre as relaçóes raciais e os modos de ser das classes sociais, as conexôes históricas entre mundos marcados pelos impérios europeus e pela escravidão, a história dos preconceitos raciais - e sua negação -, e a experiência da fronteira e da migração sucessiva. Enquanto herdeiros da transformação americana dos impérios ibéricos, e com inserçóes igualmente complexas e paradoxais no conjunto da América Latina, o enfoque comparativo entre o Caribe e o Brasil permite repensar questóes centrais para a relação entre cultura e experiência colonial, revalorizando assim uma história atenta aos lugares e tempos específicos, aos corpos, linguagens e registros da voz, ao imaginário e sua força.

O livro formula perguntas da maior relevância e complexidade, por exemplo: como é que o Bra- sil foi lido e escrito pelos intelectuais do Caribe? E como o Caribe foi pensado por intelectuais brasileiros? E a resposta, como aparece na "Nota para esta antologia”, vem de sua própria trajetória intelectual, uma vez que o autor se indaga sobre os modos pelos quais o Caribe e o Brasil foram emergindo na sua experiência profissional.

Focando a relação entre cultura e política, o livro repropóe os problemas do nacionalismo e do imperialismo como profundamente interligados, sob uma perspectiva crítica pós-colonial. De fato, a questão da tradução entre línguas e culturas constitui um de seus núcleos fundamentais: como revelam a introdução de Pedro Meira Monteiro e suas instigantes notas de rodapé, a tradução não constitui nele simples tarefa técnica de intermediação, mas sim trabalho de investigação que assinala os núcleos problemáticos, os obstáculos e impossibilidades - e, inclusive, em muitos casos, a intraduzibilidade. Nos diferentes contextos de leitura e circulação desses ensaios, as palavras revelam-se como marca das relativas convergências e divergências entre a história do imperialismo no Caribe hispânico e no Brasil, ambos parte do mundo colonial do século XIX e pós-colonial contemporâneo. O ensaísta investiga o mundo do Caribe como marcado pela condição colonial e pós-colonial, incluindo a experiência da diáspora, da escravidão e da guerra - e também da revolução, da ocupação militar e do turismo -, de modo tal que permite colocar em questão as próprias ideias de Estado e nação como universos fechados.

Nesse sentido, a comparação tem o potencial de revelar o modo como o discurso nacionalista no contexto colonial atuou como negação e afirmação da pretendida universalidade do modelo metropolitano de Estado-nação. As nações americanas - o Brasil e as do Caribe -, mimetizaram as práticas europeias, mas também revelaram sua própria concepção da história. A comparação, desse modo, revela como o discurso nacional é um discurso da autonomia ao mesmo tempo que da subordinação. Esse discurso, que emula a cultura dominante, imperial, também a questiona, mas preservando a validez do paradigma e sua relação com a modernidade.

Como assinalou Partha Chatterjee (1993), o nacionalismo, que compartilha as mesmas premis- 
sas materiais e intelectuais do Iluminismo europeu, leva implícita a ideia de que as regióes coloniais, não europeias, não têm alternativa histórica fora de tentar aproximar-se dos atributos de modernidade das metrópoles, quando esse mesmo processo implica em sua continua subordinação a uma ordem mundial que não podem controlar. Segundo Chatterjee, a questão nacional não pode ser pensada separada da questáo colonial, nem da construçáo do conhecimento no pós-Iluminismo, dado que sua base moral e epistêmica é parte de um marco universal que perpetua a dominação colonial. É nesse sentido que Chatterjee afirma que o discurso nacional subordina-se à premissa de modernidade, na qual a dominação colonial esteve baseada. Essas reflexóes permitem repensar a história do Caribe e do Brasil a partir do mundo colonial, assim como sua igualmente complexa inserção no universo de pertencimento "latino-americano".

Com enorme sensibilidade crítica, os ensaios de Díaz-Quiñones constroem uma cadência permanente entre cultura e sociedade, entre experiências e representações, analisando o modo como as palavras atuam, na tradição das keywords de Raymond Williams (1983), isto é, como um vocabulário compartilhado de sentidos, práticas e instituições, que, mais que uma tradição a ser aprendida ou respeitada, revelam conflitos de valores e crenças ligadas a condiçóes sociais e históricas precisas e sujeitas à mudança e à descontinuidade. Díaz-Quiñones ilumina nos múltiplos e conflitantes usos de palavras centrais para a tradição cultural do Caribe hispânico a carga política e afetiva do ato de nomear e a significação como ato político. Os ensaios constroem um território que ultrapassa as fronteiras das disciplinas e se coloca entre a história cultural, a crítica literária, a teoria política, a história intelectual e a sociologia; além disso, conjuga a análise de obras literárias e culturais canônicas com a investigação do mundo da oralidade e da cultura midiática e popular. Por outro lado, tanto no caso dos artigos mais acadêmicos quanto nos textos de intervenção, a prática do ensaio, para Díaz-Quiñones, implica um distanciamento de toda ilusáo de totalidade ao mesmo tempo que um compromisso com a contemporaneidade: $\mathrm{o}$ ensaísta recua diante de qualquer solução épica ou de qualquer retórica dogmática diante dos dilemas políticos e culturais próprios do colonialismo e pós-colonialismo e reivindica o papel dos intelectuais e das populaçóes da diáspora como partícipes solidários dos eventos políticos, dos valores culturais e da própria integridade das ilhas. Os ensaios refletem sobre a memória, em sua relação com a história e com a autobiografia intelectual, a partir de perguntas como: Como é que as comunidades e as sociedades da diáspora recordam? O que significa a memória histórica no mundo pós-colonial das tecnologias modernas e da mídia? Qual é o papel dos intelectuais, dos homens e mulheres da política e da cultura, nas recordaçóes coletivas?

O primeiro ensaio, "De como e quando bregar", adentra-se nos múltiplos cenários da vida porto-riquenha para examinar a "brega" como metáfora estratégica para entender as dinâmicas da cultura e da política em Porto Rico.

Vale a pena, neste ponto, uma breve explicação sobre o significado da metáfora de "bregar" e seu uso na sociedade porto-riquenha. Como assinala Pedro Meira Monteiro na introdução, "A arte de furtar-se", o verbo "bregar" é um enigma a ser traduzido: ele é utilizado entre porto-riquenhos dentro e fora da ilha - para determinar o ato de, segundo Monteiro, "lidar delicadamente com uma situação difícil [...] tão humanamente quanto possível [...] evitando a dureza do confronto definitivo". Como afirma Díaz-Quiñones, "bregar" é "um método difuso e sem alarde para navegar a vida cotidiana, onde tudo é extremamente precário, cambiante ou violento”. A brega é própria daquele que encontra espaço e ar numa situação adversa, através de gestos sutis de resistência que permitem pensar o político, mais do que através de grandes atos, no cotidiano e nos desvios sutis. A brega, mais do que uma essência da nacionalidade ou uma marca do civilização tropical, é uma prática e uma experiência desenvolvida pelos sujeitos - migrantes, sem pátria, semiletrados e plurilíngues.

Nesse sentido, a brega revela os caminhos sutis, antitrágicos, pelos quais a língua falada e a cultura contemporânea remete à tradição colonial, ao mundo da plantação e contra-plantação, às práticas de ocultamento e às sociedades clandestinas. Com base na análise de figuras centrais da política e da cultura porto-riquenha, da música popular, da li- 
teratura, do esporte e da cultura midiática, visual e oral - atravessadas pelo bilinguismo, pelas migraçóes sucessivas e por uma dinâmica sempre dupla -, o ensaio examina a coexistência conflitiva entre alteridades culturais e étnicas que nem se cindem nem se fundem por completo, entrando em equilíbrios momentâneos e frágeis. Trata-se de um conjunto de cenas - discursos, práticas, representações que iluminam os modos pelos quais os sujeitos lidam com a precariedade da emigração e da cidadania, com os preconceitos raciais e os dilemas da tradução entre impérios, criando modos de adaptação em espaços sociais restringidos. Desse modo, o ensaio aponta para a complexidade da experiência colonial, da vida no interior de instituiçóes marcadas pela duplicidade e por lealdades coloniais irreconciliáveis. A análise da carga afetiva e política da "brega", como sintoma de uma cultura efêmera e em trânsito, marcada por mudanças e relocalizaçóes, revela as contradiçóes de uma ideia autossuficiente de cultura, ao mesmo tempo que desmente qualquer integração fácil à cultura dominante. Ressalta, assim, a impossibilidade de monopolizar o "nós" coletivo da ilha, localizado em diferentes espaços de autonomia relativa e participação da vida porto-riquenha.

O segundo capítulo, "Hispanismo e guerra", estuda a formação histórico-cultural do hispanismo e sua presença na Espanha, no Caribe hispânico e nos Estados Unidos, a partir da Historia de la poesía hispanoamericana (1911-1913), de Marcelino Menéndez Pelayo, primeira obra sistemática sobre a poesia hispano-americana feita na metrópole. O texto revela a necessidade ideológica premente, no contexto posterior à guerra hispano-cubano-norte-americana, de restaurar a preeminência da Espanha como centro legitimador, recompondo o projeto imperial através da reconciliação com as velhas colônias. No ensaio, Díaz-Quiñones aponta para o que foi apagado e suprimido do livro de Menéndez Pelayo, emblema da civilização, do cânone letrado e de suas hierarquias: a violência e o aniquilamento da população indígena, o contato com as línguas e culturas africanas, a persistência das demarcaçóes raciais, o lugar crescente dos Estados Unidos e as lutas e resistências dos hispano-americanos. Através da história dos usos cambiantes e variados do hispanismo - seja como sinônimo do americano e colonial, como rejeição do bárbaro e contrário à ilustração ou como símbolo da aliança diante do avanço da hegemonia norte-americana -, o estudo revela as operaçóes de identificação e distanciamento próprias da relação contraditória e conflitiva entre colônia e metrópole. Ainda mais, Díaz-Quiñones examina o ressurgimento do hispanismo no contexto da restauração dos estudos hispânicos na academia norte-americana, reproduzindo as exclusóes e dilemas próprios de velhos e novos colonialismos: a subordinação das literaturas hispano-americanas, a impossibilidade de pensar o mundo cultural afro-caribenho e a supressão das práticas culturais híbridas que não necessariamente correspondem à cultura letrada impressa. A partir do foco no espaço inominável, para as fontes letradas de entâo, do mundo fronteiriço da plantação e contra- plantação, da escravidão e das populações desertoras e migrantes das ilhas, o ensaio ilumina o modo como o Caribe permite "provincializar" a identidade hispânica metropolitana, mostrando seu caráter conflitivo, suas fugas e exorcismos, e questionando qualquer noção estável de identidade. Desse modo, como já foi assinalado por Dipesh Chakrabarty (2000) e o projeto historiográfico dos estudos subalternos, em lugar de símbolos do atraso e do anacronismo no mundo político em rápida modernização, as sociedades coloniais constituem elementos fundamentais da modernidade, capazes de colocar a própria identidade metropolitana em questão.

O terceiro capítulo, "A guerra simbólica: 1898”, investiga uma série de produçóes simbólicas e imagens da cultura de massas em torno da guerra hispano-cubano-norte-americana. Essas produçóes constituiriam, no plano cultural, modos de decifrar, comentar e reproduzir as formas de posse destinadas a consolidar o controle militar e comercial dos territórios, alimentando, ao mesmo tempo, a imaginação dos leitores. Desse modo, a fotografia, publicada em livros de viagens, revistas e guias, aparece como parte fundamental da intervenção militar no Caribe e da construção do olhar imperial, revelando a sedução exótica e cientifica das ilhas. Ainda mais, no contraste entre esses usos e códigos do fotográfico e a imprecisão e irredutibilidade das próprias imagens, o ensaio demonstra que elas tornam discutível qualquer binarismo. 
O quarto capítulo, "Espiritismo e transculturação. Fernando Ortiz e Allan Kardec", examina o interesse do intelectual cubano pelo espiritismo, que lhe oferece ferramentas para repensar a questão racial a partir de uma perspectiva evolutiva que abarca espiritualidade, ciência e religião. Através da conjunção de espiritismo e cientificismo, Ortiz consegue, na leitura de Díaz-Quiñones, reinterpretar o lugar do africano na cultura cubana em termos de uma teoria evolucionista da alma e da nação.

Por outro lado, o quinto capítulo, "A memória rota" traça uma linhagem de intelectuais, políticos, escritores, e críticos culturais porto-riquenhos que revelam modos de reabilitação da memória diante do entusiasmo otimista e acrítico com a civilização tecnológica e com a modernização como destino irreversível. Díaz-Quiñones descobre nesse mapa genealógico de intelectuais que pensaram a cultura como crítica e debate - e que se rebelaram contra o esvaziamento do debate público e político - novas possibilidades para conceber a relação entre memória, história e cultura na sociedade.

Os ensaios, assim como a nota introdutória e a entrevista final, revelam um projeto intelectual que recusa qualquer solução dogmática, de caráter épico ou heroico, assim como qualquer tendência ou escola única do pensamento, para dar conta, através de uma mirada sutil, da precariedade, a ambivalência e o esvaziamento próprios da experiência colonial e pós-colonial. Para isso, Díaz-Quiñones vale-se de uma multiplicidade de fontes, reflexóes e disciplinas - produzidas na academia norte-americana, na América hispânica, na Espanha e no mundo -, para fazer do pensamento social uma forma de aproximação não totalizante, mas conflitiva e complexa, de afirmação e recusa, de idas e vindas, perante os dilemas da sociedade e a cultura.

Díaz-Quiñones foi um pioneiro ao denunciar a indiferença da crítica latino-americanista diante do Caribe, e especificamente de Porto Rico, até algumas décadas atrás, ao qual se conferiu um lugar incerto, como fronteira desprezada e carente de subjetividade histórica, sem complexidades internas nem tensóes políticas ou afetivas. Essa negação e mutilação do estatuto de Porto Rico, como um "outro" aparentemente unívoco, que serve só para fins de contraste com a identidade nacional aceitá- vel, é parte das estratégias de saber e poder do discurso colonial, praticadas no interior da própria disciplina crítica. Não é casualidade que, como intelectual público, historiador cultural e crítico literário, Díaz-Quińones deu origem a uma nova geração de pesquisadores e críticos que vem estudando a América hispânica, o Brasil e o Caribe, iluminando as relaçôes entre nacionalismo e colonialismo, suas hierarquias e apagamentos, e os modos pelos quais a identidade torna-se espaço de renovação, criação e cruzamento no mundo pós-colonial.

\section{BIBLIOGRAFIA}

CHAKRABARTY, D. (2000), Provincializing Europe: postcolonial thought and historical difference. Princeton, Princeton University Press.

CHATTERJEE, P. (1993), Nationalist thought and the colonial world: a derivative discourse. Minneapolis, University of Minnesota Press.

WILLIAMS, R. (1983), Keywords: a vocabulary of culture and society. Nova York, Oxford University Press.

\section{ALEJANDRA JOSIOWICZ é mestre e doutora em língua e cultura brasileira e hispano-americana pela Princeton University e pós-doutoranda na Casa de Oswaldo Cruz (COC-Fiocruz) com bolsa da Faperj. \\ E-mail: alejandra.josiowicz@gmail.com.}

DOI: $10.17666 / 329412 / 2017$ 